\title{
Entrevista com Rose Clér Estivalete Beche - Coordenadora do Nú- cleo de Acessibilidade Educacional - NAE - UDESC
}

\author{
DOI: http://dx.doi.org/10.5965/1984317815042019251
}

Rose Clér Estivalete Beche possui graduação em Pedagogia pela Universidade Federal de Santa Catarina (2002) e mestrado em Educação pela Universidade Federal de Santa Catarina (2005). É doutoranda do Programa de Pós-Graduação em Educação da UDESC. Atua como professora no Centro de Educação a Distância da Universidade do Estado de Santa Catarina, coordena o NAE, Núcleo de Acessibilidade Educacional da UDESC. Ministra disciplinas na área da Inclusão e Diversidade na Universidade do Sul de Santa Catarina/UNISUL.

REAI - Qual a sua experiência de inclusão na UDESC?

Estou na Udesc há cerca de 15 anos e desde então trabalho com diferentes âmbitos do processo inclusivo. Fui contratada inicialmente como professora colaboradora para trabalhar no curso de Pedagogia a Distância, no qual tinham turmas de estudantes cegos e de estudantes surdos. Desde então, participei das diferentes iniciativas propostas pelas gestões. Dentre estes, quero registrar o COMINC (Comitê de Inclusão) que oportunizou discussões instigantes, mas que não conseguiu de forma significativa efetivar as ações planejadas. Após minha efetivação como docente participei e, coordenei o LEdl (Laboratório de Educação Inclusiva) que agrega projetos de ensino, pesquisa e extensão na área visando a difusão dos preceitos inclusivos e a quebra de barreiras de acessibilidade. Mas foi em 2015 como coordenadora do NAC (Núcleo de Acessibilidade do CEAD) em atendimento aos estudantes com deficiência e/ou especificidades educacionais do Curso de Pedagogia a Distância que percebi a grande lacuna existente em nossa Universidade no que tange ao atendimento desta parcela da população. No final de 2017 fui convidada a integrar a equipe que discutia o projeto do NAE (Núcleo de Acessibilidade Educacional) junto à Pró-Reitoria de Ensino. Com uma equipe comprometida e atuante foi possível a institucionalização no início de 2018 assumindo a sua coordenação e deflagrando o processo de efetivação de ações para toda a universidade.

REAI - Como tem sido a inclusão de pessoas com deficiência no Ensino Superior da UDESC?

Nossos estudantes com deficiência e/ou especificidades educacionais foram mantidos na invisibilidade salvo por ações realizadas pontualmente em alguns Centros. Sempre que necessitaram de algum tipo de adequação (de tempo, mobiliário, curricular) precisaram "negociar" junto ao corpo docente e chefias de departamento. Ações que ficavam no âmbito individual e não como uma política implementada na universidade. Há que se considerar que esta cultura traz consigo uma bagagem que 
se aproxima do privilégio, deixando os estudantes em situação de exceção o que, longe do direito preconizado em lei, traz desconforto perante seus pares. Assim, o NAE iniciou suas ações mapeando os estudantes com deficiência e/ou especificidades educacionais por meio da matrícula e rematrícula. A partir destes dados foi possível oferecer o apoio do Núcleo e realizar os procedimentos de atendimento às necessidades apontadas pelos estudantes. Esta etapa do processo tem sido construída em parceria com os estudantes, público-alvo, com os docentes e Chefes de Departamentos envolvidos na busca de superação das dificuldades vividas.

Outra ação de grande relevância é o apoio à criação dos Núcleos de Acessibilidade nos Centros. Por sermos multicampi, o gerenciamento do atendimento torna-se moroso e dificultoso se centralizado no Campus 1, onde hoje é a sede física do NAE. Também temos perfis muito diferentes de estudantes devido ao espectro de cursos que oferecemos e, logicamente, muitas necessidades também diferenciadas que podem ser melhor atendidas por profissionais que conheçam profundamente estas diferenças e que, pela proximidade física, mantenham uma comunicação eficiente realizando o exercício da escuta e juntos, profissionais e estudantes, planejem as ações a serem realizadas.

Realizamos, em 2018, a I Jornada de Inclusão da UDESC, um evento que de forma tímida objetivou iniciar a discussão com os pares, Coordenadores de Núcleos de Acessibilidade de Universidades federais e estaduais, através da partilha de experiências. Este ano, a $2^{a}$ Jornada trouxe convidados das IES de diferentes Regiões do Brasil e dos Estados Unidos, visando conhecer como o processo de inclusão acontece naquelas instituições. Esta ação oportunizou também uma aproximação entre os representantes dos Núcleos de Acessibilidade de instituições de Santa Catarina e a configuração de um novo espaço de interlocução, fortalecendo o processo inclusivo dentro da nossa instituição.

Com a atuação do NAE, e com ele, os NAEs setoriais, é oferecido aos estudantes, desde que matriculados e autodeclarados, o direito a ter suas necessidades educacionais atendidas. Sabemos que independente da autodeclaração, todos deveriam ter suas necessidades atendidas, para tanto, há necessidade de uma reorganização institucional mais profunda que pode ser alcançada de forma processual.

Acreditamos que os princípios inclusivos se baseiam no conceito de equidade e para alcançar a todos, indistintamente, precisamos criar uma cultura de respeito e aceitação das diferenças, que fazem parte das subjetividades humanas.

REAI - Qual o papel do NAE nesse contexto?

O NAE torna-se, paulatinamente, o espaço promotor de uma outra forma de olhar nossos estudantes a medida que oportuniza a garantia de direitos e auxilia o processo de inclusão. Se inicialmente, coube ao NAE justificar sua existência através da legalidade, hoje, após 21 meses de funcionamento, nos cabe difundir ainda mais os preceitos inclusivos alcançando toda comunidade e minimizando o preconceito e a discriminação que, culturalmente, exclui e elitiza um espaço que é público. 
REAI - Que perspectivas você vislumbra para ampliar a entrada e permanência de pessoas com deficiência a longo prazo?

Precisamos urgentemente de uma política de acessibilidade em nossa universidade. Necessitamos discutir, sob os preceitos inclusivos, que universidade queremos oferecer; que espaço educacional todos os nossos estudantes merecem ter; qual a nossa real contribuição como Instituição de Ensino Superior queremos deixar como legado ao povo catarinense.

Almejamos tornar nossa Universidade referência no acolhimento às diferenças e este é, com certeza, o maior desafio e norteia nossas próximas iniciativas.

REAL - Que documentos nacionais e ou internacionais tem amparado a inclusão de pessoas com deficiência no Ensino Superior?

Certamente a mais recente e significativa é a LBI - Lei Brasileira de Inclusão que garante no seu Capitulo IV as condições para que as pessoas com deficiência tenham assegurado, para além do acesso, a permanência e o sucesso em todos os níveis e modalidades de ensino. Não posso deixar de mencionar, também, a Convenção sobre os Direitos das Pessoas com Deficiência, aprovada pela ONU em 2006, ratificada no Brasil com força constitucional pelo Decreto Legislativo n. 186/08. Essa Convenção foi um marco na legislação brasileira e trouxe uma outra forma de compreensão da deficiência, vista como relacional, apoiada no modelo social de deficiência.

REAI - Agradecemos sua entrevista e solicitamos que você possa nos deixar uma contribuição final.

A história do Nae está sendo construída com o princípio da parceria onde todos os envolvidos são ouvidos e respeitados constituindo um ambiente de alteridade, no entanto, vislumbramos outros grandes desafios a serem superados. Fomentar a aproximação da pesquisa e da extensão com o campo da inclusão poderá modificar as concepções de deficiência baseadas na menos valia e no déficit.

Quiçá, como fruto deste processo, possamos contribuir ainda mais para que a universidade pública possa cumprir com maior excelência seu compromisso social de se tornar um espaço de produção de conhecimento acessível e acolhedor a todos, indistintamente, em um processo onde as diferenças individuais agregam valor e contribuem significativamente superando o individualismo e a exclusão.

Agradecemos a entrevista.

Entrevista concedida à Equipe Editorial da Revista Educação, Artes e Inclusão em Setembro/2018. 